ISSN: 2162-3104 Print/ ISSN: 2166-3750 Online

Volume 8, Issue 4 (2018), pp. 1722-1735

(C) Journal of International Students

http://jistudents.org/

doi: 10.5281/zenodo.1468076

\title{
International Graduate Students' Challenges and Learning Experiences in Online Classes
}

Tala Michelle Karkar-Esperat

Texas Tech University, USA

\begin{abstract}
The purpose of this case study was to identify the learning experiences and examine the challenges facing three international graduate students enrolled in online, asynchronous classes in an American public university. Applying the lens of constructivism, data were collected from a questionnaire, semi-structured interviews, and a focus group. Findings from the study indicate that the students faced challenges with English language proficiency, isolation, instructor's lack of experience, and a lack of motivation to study in online classes. Notwithstanding, students described flexibility and convenience as key factors of the learning experiences in a virtual classroom. Implications for administrators and course designers in understanding student perspectives of online classes and best practices for conducting asynchronous classes are provided.
\end{abstract}

Keywords: asynchronous class, international student, online class

International graduate students encounter academic and cultural difficulties when they begin their studies abroad. In this study, the term "international graduate students" refers to students from countries outside the United States who are enrolled in a graduate program at a university within the United States. Some of the challenges and hurdles attending higher education institutions in the United States emerge from difficulties in adapting to a new culture, feelings of isolation and alienation, language limitations, and complications in communication with their professors and peers (Byram \& Feng, 2006; Erichsen \& Bolliger, 2011; Han, 2007; Hofstede, 2005). Rawlings and Sue (2013) asserted that these difficulties lead international graduate students who are exposed to a new culture to encounter challenges in assimilating to the new context leading them to feel lonely and depressed.

Yet, computer-based learning or online learning has become a popular alternative teaching method in many institutional organizations all over the world (Allen \& Seaman, 2014; Ko \& Rossen, 2017; Sawang, Newton, \& Jamieson, 2013). In fact, the enrollment in online classes increased from 2 million in 2003 to 6.7 million in 2014 (Allen \& Seaman, 2014; Simonson, Smaldino \& Zvacek, 2015; Tootoonchi, 2016). Moreover, this form of enrollment has been determined to be the most popular mechanism for graduate students (Harasim, 2017).

Given the challenges facing international students and the popularity of this learning platform for graduate students, this study examines the challenges faced by three international 
graduate students and the learning experiences that accompany these challenges in the last three years. Identifying the challenges in an online environment will allow practitioners and policy makers to create guidelines for instructors designing and teaching online classes by focusing on the students' technology capabilities and needs.

\section{RESEARCH QUESTIONS}

The purpose of this study was to examine the challenges of online, asynchronous classes faced by three students in an American public university and to understand the learning experiences accompanying these challenges. The study was guided by the following questions:

1. What are the perceptions of international graduate students in the online course over the period of one semester?

2. How do international students perceive learning in an online course environment in relation to information acquired and level of satisfaction?

3. What are the major challenges faced by international graduate students in the online learning, asynchronous class environment?

4. What features do international students prefer in the design and delivery of an online asynchronous class environment?

\section{LITERATURE REVIEW}

\section{Background}

The population of international students seeking graduate degrees in the United States has increased since the turn of the century (Einaudi, 2011). International student populations enrich the culture and the diversity of American universities. They expose domestic students to diverse cultures and languages. Some universities offer certain courses only online; therefore, students do not have the face-to-face instruction option of a traditional program. While online education has become a more accepted form of study in the United States that has not always been the case in other countries (Haynie, 2014). For this reason, international students are less likely to have experienced taking online classes.

Presently, most students use technology on a daily basis. They can access the Internet on a multitude of platforms, including their cell phones. Navigating the Internet is not as difficult as it once was. Zhang and Kenny (2010) proposed that many teachers use some form of instructional technology in their classes. Moreover, some universities are offering exclusively online education programs, as experienced through computer-mediated communication. Online education meets the needs of its participants' lifestyles to manage time conflicts and personal commitments, and to access course materials from different locations. Many international students sign up for online programs, but others prefer face-to-face, classroom learning. However, some of the students who had traveled thousands of miles away from home to be in traditional classes found themselves taking online courses because the university where the study was conducted had converted some of their face-to-face courses to online only. There are both advantages and disadvantages in taking online courses. The issue for these international students is to understand whether the benefits of taking an online class outweigh the challenges. 


\section{Satisfaction with Classes}

There are specific strategies that instructors can use to improve student satisfaction with online classes. Cole, Shelley and Swartz (2014) explored student satisfaction with online learning. They found that the instructor's promptness, clarity of instructions, and capability to effectively use technology to deliver online courses affect student experiences in taking online classes. Furthermore, Jackson, Jones, and Rodriguez (2010) revealed that students preferred face to-face classes over online classes for a variety of reasons. With traditional classes, the instructor's promptness in responding to students' emails and concerns was higher. In online classes, students faced difficulties in accessing the course, and course expectations were not clearly stated. Most importantly, instructor enthusiasm played a significant role in student satisfaction in traditional classes.

Wickersham and McGee (2008) found that low interaction in online classes subsequently led to low satisfaction in the overall online course experience. Lee (2010) investigated online support service quality, online learning acceptance, and student satisfaction; this study was conducted through student questionnaire to explore their perceptions of the quality of support services. Lee deduced that the perception of service quality affects behavioral purposes of online learning and user's satisfaction. For example, students who were required to hold when calling the support center or wait days to receive a reply to an email in request for technical assistance became dissatisfied with the online course itself. Furthermore, quality of service impacts recognition of easy to use and effectiveness of online education. The results of Lee's study indicated that service quality can enhance acceptance and satisfaction with online educational services. Lee concluded that students must be supported both individually and institutionally. Instructors' awareness of the disadvantages of taking online classes can help them adopt practices to lessen the impact of those challenges.

\section{Advantages and Disadvantages of Online Classes}

There is sufficient literature that highlights the positive and negative consequences of online courses for international graduate students. For instance, $\mathrm{Ku}$ and Lohr (2003) studied Chinese students' perceptions of their first online class, and their study revealed some of the advantages of online classes. Participants in the study stated the advantages of online classes: one advantage was the online classes required "real" participation and actual effort. Fewer language barriers existed since students had to use only reading and writing skills without the confounding influence of colloquialisms, idioms, or slang. Guernsey (1998a, 1998b) noted that students from a variety of disciplines appreciate factors of online classes such as, flexibility, convenience, and a lack of required travel. Flexibility allows students to access the material at any time and any place. Students in asynchronous communication fulfill the class requirements by working at their own pace (Guernsey1998a, 1998b).

Online classes have provided an interactive learning environment that allows students to exchange information, gain knowledge and diverse experience through social context. According to Biesenbach-Lucas (2003), such that "non-native and less verbal students tend to keep silent in face-to-face class, they felt comfortable participating more fully in electronic discussions" (p. 36). Furthermore, Biesenbach-Lucas concluded that the social benefits of the discussion group helped students build social interactions among each other. They supported each other and exchanged experiences and ideas.

Less positive experiences with taking online courses have been mentioned in literature. Students have reported feeling isolated (Cragg, 1994a, 1994b; Landis \& Wainwright, 1996). 
They believed that they lacked peer support, hence, they felt isolated (Ku \& Lohr, 2003). Some students did not provide constructive feedback, and online classes lacked the language and culture exchanges. Additionally, there is minimal interaction with students in an asynchronous, online course. Instructors tend to not immediately respond to student queries if they are unable to check their emails everyday. This leaves students very frustrated because if there is an immediate response needed for an upcoming assignment, students are not getting the timely support needed to get through the weekly assignments (Frimming \& Bordelon, 2016; Vonderwell, 2003)

Hardware and software problems have also caused frustration among students and instructors. Negative instructional issues have been identified such as the instructors' lack of proficiency with certain software. Students expected instructors to have the technical proficiency to allow them to focus on working on the course rather than focusing on technical issues (Morse, 2003). Other students reported that online classes require self-discipline that they lacked, to complete their work on time. Students' initial challenge with online courses is with the design of the course.

\section{Features in Online Classes}

Certain features of online courses have been determined to contribute to a more positive experience for international graduate students. For instance, Shea, Li, Swan, and Pickett (2006) examined a group of online students' sense of community learning, as measured by Rovai's (2002) Classroom Community Scale, and the teaching presence, as measured by indicators that reflect components of the community of inquiry model. The study consisted of 2,036 participants across 32 campuses of the State University of New York College. Shea et al. recommended some features to be included in online course designs. First, they argued that the goals and topics of online courses need to be clear and well communicated to the students. Second, course activities and time parameters need to be stated clearly and documented. Third, the instructor needs to provide clear instructions on how to participate in an online discussion and should provide methods and guidelines about interactions that take place on the discussion board.

\section{THEORETICAL FRAMEWORK}

The design and principles of online distance education courses have tended to be based on social constructivist theory (Jonassen et al., 1995; Moller, 1998; Petraglia, 1998). In this study "course design" refers to the structure of the course and how the material is organized. According to social constructivist theory (Vygotsky, 1978), teachers are the facilitators of the educational process, and learning is a social activity. Teachers create the learning environment and maximize student learning by choosing meaningful and challenging tasks, encouraging peer collaboration, giving adequate feedback, and providing guided instruction. Learning takes place in an authentic environment such as asynchronous communication that allows social negotiation to occur across time and distance (Doolittle, 1999). Thus, students are encouraged to be self-mediated and self-aware (Brooks \& Brooks, 1993).

Some of the essential factors in the constructivist pedagogy are that teachers serve as facilitators of learning and present the content in various ways from different perspectives. Vygotsky (1978) envisioned interaction among peers as an effective way of developing skills and knowledge. Furthermore, in a constructivist classroom, learning involves social negotiation and mediation, as social interactions help students develop their communication skills and 
overcome their avoidance of interacting with other students (Miltiadous \& Savenye, 2003). Teachers can create a collaborative community using group-based instruction, managing dialogue among students to promote deeper learning, and acknowledging student contributions.

Vygotsky (1978) proposed that interaction among peers effectively promotes the development of skills and knowledge. Online classes have provided students opportunities to internalize their experiences and write about something that was meaningful to them, encouraged them to share their knowledge, and given them a way to ask meaningful questions in any environment. As such, social interactions among peers play a vital role in learning. Yet, as demonstrated earlier, the benefits of social constructivism for enhancing online learning for international, and by extension, international graduate students are often overlooked. Instead, theories, like theory of communicative action that underlies examinations of these students' experiences, tend to be focused on social constructivism. Therefore, social constructivism provided a useful avenue to examine the experiences of international graduate students via a qualitative approach

\section{RESEARCH METHOD}

\section{Research Design and Context}

Creswell (2009) noted that "case studies are a strategy of inquiry in which the researcher explores in-depth a program, event, activity, process" (p. 13). A case study examines the details of a setting, subject, or a particular event (Merriam, 1988). The goal of an exploratory case study is "not to conclude a study but to develop idea for further study" (Yin, 2003, p. 20). This qualitative study conducted, from January to May 2016, used the case study design to explore the use of online learning by international students. Thus, the context of the study was the online graduate program of a specific College in a particular university. This college included nine masters and ten doctoral programs. The programs in which the participants were enrolled were the most popular in the College. These programs had been described by students and professors as useful for graduate students and therefore provided a key context for this examination. Within this context, the study explored the challenges of online classes for international graduate students, their perceptions of taking online classes, and the features they preferred in the design and delivery of the courses. The case study proved appropriate to examine the online learning of international graduate students in context as a means of answering questions related to the "why" and "how" (Baxter \& Jack, 2008) based on patterns in previous studies that investigated the challenges that international students experienced while taking online classes. This study examined graduate international students who have been in the United States for less than five years. They share their experiences based on their newcomer status and their previous and current experience of taking asynchronous online classes. This work is one of few recent studies that include Master's and PhD students who have different technology capabilities, backgrounds and expertise.

\section{Participants}

Primary participants, referred to hereafter as participants, selected were two female, international doctoral students and a master's student at a large public university in the 
Southwestern United States enrolled in online asynchronous courses through Blackboard, a learning management system. These students have been enrolled in the current graduate programs for at least 16 months. They were selected through purposeful sampling, using the maximum variation sample method (Lincoln \& Guba, 1985). Purposeful sampling was employed because the researcher was interested in exploring international students' experiences in online courses and recruited participants accordingly. The first participant, Olga, was from Turkey and had been living in the United States for four years. The other two participants (Katie \& Abby) were from South Korea from rural and metropolitan city, and had been living in the States for three years. Abby, Katie, and Olga had each completed at least four online courses and pursued programs in Curriculum and Instruction with the focus on STEM education, and Katie is in the Teacher Education program. Participants were all between the ages of 30-39 and they were multilingual. The participants' newcomer status and diverse backgrounds assisted the researcher in answering the questions of the study and learning about the challenges of taking online classes, their perceptions of online classes, and the web design features that increased their satisfaction with online classes.

Permission was obtained from the course instructor to conduct the study. This instructor possessed a $\mathrm{PhD}$ degree in Curriculum Studies, was born in Korea, and adhered to the procedures of online instruction in this course. The instructor was also eager to learn how to improve instruction in her course.

\section{Data Collection}

Upon obtaining the Institutional Review Board approval and permission from the course instructor, participants signed and returned the consent form before completing the required questionnaire. Face-to-face semi-structured interviews, each approximately 50 minutes long, were then conducted with each participant. Following the completion of questionnaires and interviews, the researcher conducted a focus-group interview discussion with all three participants, which lasted approximately one hour long.

Data sources included three face-to-face interviews, one questionnaire, one focus-group interview, field notes, and a researcher's journal entries. Semi-structured interviews (Merriam \& Tisdell, 2016) allowed for open-ended questions in order to obtain more natural, in-depth data. The researcher wanted to make the interviewee as comfortable as possible during the entire process, taking "advantage of the respondent's spontaneity rather than stifling in an attempt to keep the interview on track" (Erlandson, Harris, Skipper, \& Allen, 1993, p. 90). The interview protocol contained a list of 18 open ended questions with information required concerning the structure of the online classes they have taken, their overall experience with the discussion board and their experiences with the activities designed in their classes, the challenges of taking online classes, and the strategies they used to deal with these challenges. Questionnaires helped to provide information about the participants' demographics and comfort with online classes. The questionnaire used in the study provided flexibility for respondents so they would feel free to express their own perspectives on issues. Factors that increase response rate were taken into account in designing the layout of the questionnaire (Marshall, 2005). The researcher started with easy, non-threatening questions to increase the response rate. The questionnaire included a list of 13 questions and ranged from information concerning their level of comfort in using technology, their experience of taking online classes, and how their instructor's knowledge of technology had an impact on their success in the course. Focus group interviewing, a popular data collection strategy and considered "the best way to get to the best data that addresses your research questions" (Merriam \& Tisdell, 2016, p. 115), allowed for 
collaboratively gaining meaning from individuals who all had information about the topic under study. This mechanism created an opportunity for "interactive discussion through which data are generated, which leads to a different type of data not accessible through individual interviews" (Hennik, 2013, pp. 2-3). The focus group interview protocol consisted of a list of eight questions that extended the information gathered from the individual interviews with and questionnaires completed by the three participants. Field notes were compiled weekly From January- May. The researcher's journal (Plath, 1990; Yin, 2014) provided an outlet to describe the process of conducting this study, reflections on the interviews, and the field notes that the researcher gathered while conducting the interviews and the focus group interviewing.

\section{Data Analysis}

The face-to-face interviews were recorded using a voice recorder, and the researcher took notes throughout the interview to increase validity. All audio recordings were transcribed. Data in the transcript were categorized into themes. Additionally, reflective journal entries were used to triangulate the data. The researcher used the open coding approach to code the data by using line-by-line and paragraph-by-paragraph coding throughout the analysis.

After reviewing all the data gathered, the researcher analyzed the responses based on the research questions. To answer the first research question, "How do international students perceive learning in an online course, in terms of how much information they acquire and their level of satisfaction?", the researcher examined the students' responses, provided in the interview, questionnaire, and identified significant statements and quotes that conveyed the participants' experiences with online courses. The researcher highlighted the keywords and then categorized significant statements and quotes under perceptions of online classes. To answer the second research question, "What are the biggest challenges that international students have to face in the online learning, asynchronous class environment?" the same process was followed. From the gathered data, a few themes were identified: language proficiency, isolation, instructor's lack of experience in teaching online courses, and students lacked motivation. To answer the third question, "What features do international students prefer in the design and delivery of an online asynchronous class environment?" the researcher followed the same steps taken to answer the first two questions and was able to identify several features participants preferred in online classes.

\section{Trustworthiness}

Credibility, transferability, and confirmability (Erlandson et al., 1993; Lincoln \& Guba, 1985) were used to contribute to the trustworthiness of the study. Credibility of the findings was obtained through triangulation of multiple sources of data (face-to-face interviews, questionnaires, field notes of the interviews, focus group, and the researcher's journal entries) and with direct quotes from participants' answers to the interview questions. Transferability was obtained through detailed description of the setting and the participants, by studying the phenomena in great detail, and by referring to previously published studies so that "findings [could] be applied in other contexts or other respondents" (Lincoln \& Guba, 1985, p. 290). Confirmability was secured by establishing an audit trail from the beginning to the end of the data collection process by using a reflexive journal and regularly documenting procedures for checking the data. For the purpose of confidentiality, pseudonyms were used to protect participants' identities, and their native language and native country were not included in the coding chart. 


\section{RESULTS}

\section{Challenges}

Findings indicated that participants faced challenges in relation to language proficiency, isolation, inexperienced instructors motivation, and the features of online classes.

\section{Language Proficiency}

Admission to the graduate program at the university where the study was conducted (i.e., a 4-year, public university in the Southwestern United States) required international and native students to demonstrate proficiency in the four language skills of the English language (i.e., reading, writing, speaking, and listening). International students were required to score 550 or higher on a computer-based test or 6.5 or better in an international English language testing system (International Prospective Students, n.d.). However, some international students who meet the minimal level of proficiency still encounter language barriers in their graduate programs. All participants found that lacking in English language proficiency presents a challenge in taking online classes (Byram \& Feng, 2006). Olga explained, "My English limits me in online classes. . . I only say a little due to the lack of my English proficiency" (I3.L320322.P9). Since online classes are heavily focused on reading and writing, not being proficient in the language is a barrier in communication. Abby said, "I am international student so to me taking offline classes is much easier because I can see their reaction, their body language, everything" (I1.L353.P10). Olga disclosed that she struggles in online classes because they are heavily dependent on writing: "I think the writing abilities is the hardest for me. I need to think and work hard on my writing and spend so much time. I get discouraged sometimes" (I3,L613614.P16). Olga was persistent to improve in her writing and, thus used different strategies. She said, "I tried to see other graduates so I ask them for help.... I also send my papers to the writing center and meet with the tutors personally to learn more about writing techniques" (I3.L591-595.P15). Like Katie, Abby faced similar struggles "sometimes I can't deliver my message very clearly.... got to think about my English a lot and I got to meet my English tutor all the time otherwise my classmate cannot understand what I am writing" (I1.L407-408.P11). Abby also mentioned that she had a very positive experience with an international professor because the professor could relate to her experience, and would push her to do better in a positive way. All participants expressed that face-to-face classes helped them avoid miscommunication and receive immediate feedback.

\section{Isolation}

Participants expressed a feeling of isolation caused by a lack of communication and interaction with their peers and the instructor. This finding is similar to Landis (2010) and $\mathrm{Ku}$ and Lohr (2003) on students' feeling isolated. They were overwhelmed by the workload so it affected their contribution to the weekly discussions. Abby expressed that she did not want to bother her classmates because she was aware that they were teachers and occupied with their jobs all day. Olga shared "to be honest, I am doing the minimal interaction, in one course my instructor said that we wanted to reply to three persons then I would reply to three persons" (F,L683-684.P18). Katie expressed that it took her a couple of trial in drafting responses to weekly discussions so she was only giving minimal effort to comply with the weekly requirements. She also said "there is no Interaction. You talk to the computer" (F,L671.P18). Olga asserted instructors did not provide activities that allowed students to actively participate 
in class. She reported that the coursework was mostly reading text and writing responses, "sometimes, I spend 20 hours on readings (I3, L256.P7).

\section{Instructor's Unpreparedness}

Participants indicated that some of the difficulties they encountered in online classes were associated with the instructor's under-preparedness in teaching online classes. Ko and Rossen, (2010) and Palloff and Pratt (2000) inferred this. They felt that some instructors struggled in creating courses in terms of structure, maintaining or uploading content, and setting due dates. Some instructors lacked experience in organizing the structure of their online courses. Abby felt that the instructor had overloaded the readings and the course was disorganized. She said " professors just pour all the assignments....one of the online classes I am taking right now is that the professor throws assignments like a swimming pool and tells the students to swim " (I1, L650.P15). This caused her to feel overwhelmed, discouraged, and unable to fulfill the class requirements. Olga said that some of the links did not work and some of the articles the instructor provided failed to open. She also said "I had a problem submitting my assignment. I asked my professor and he didn't reply and asked other classmates and they didn't help me" (I3, L604-605.P16). She also added that at the start of the semester she had difficulty navigating the courses and it was complicated for her. Olga stated that sometimes she wanted to just give up. An organized course would help students stay motivated. Additionally, there were instances in which the deadlines in the syllabus did not match the deadlines on the computermediated communication being used. Abby said that her instructor did not solve this problem, so that forced her to submit her assignments early. The instructor's lack of preparation in teaching online classes negatively affected the engagement and success of the international graduate students.

\section{Motivation}

Participants indicated that one of the major challenges in online classes was motivation. Kress, Thering, Lalonde, Kim, and Cleeton (2012) study suggested similar results. Participants indicated that it was difficult for them to stay motivated in some online classes due to the lack of interaction with classmates, the instructor's absence, and lack of prompt feedback from both their peers and the instructor. Olga said "When I don't hear feedback from my classmates and professor, I have no incentives to work hard the next time" (F,L714-715.P19). This led them to feeling discouraged. Abby's experience was different: "The professor's attitude influence us to do our best. This semester my instructor really cares about my learning. I want to do my best" (I1, L300-301.P8). Additionally, Abby and Olga felt that having a flexible schedule, and working from home made it difficult for them to stay focused and allowed them to procrastinate. However, Katie said having a schedule kept her organized and helped her meet her deadlines. Furthermore, she explained "online class helps me to be self disciplined, if I want to successfully complete the online course, I need to be disciplined keep the due date, and reading articles on time" (F, L655-657.P17). The self-discipline required for an online course is imperative for success.

\section{Features of Online Classes}

Participants expressed that they could access their coursework anytime and anywhere. Zhang and Kenny (2010) had similar findings. Participants did not feel pressured to only work at home because they could be at a conference or out of town due to work obligations, for example, and still be able to access their learning management system, Blackboard Online 
Learning. Knowing that coursework could be easily accessed, participants felt less strained in fulfilling their educational pursuits. Abby said, "I can study whenever I want. I don't need to be in the classroom but I can wisely use my time. If I have time I can log into blackboard and work. Online classes are flexible" (I1, 221-222.P7). Katie specifically expressed delight in knowing that there was an online support group, a writing support center, that could help her with her writing assignments. She said "The online writing is a great assistance for students for someone to review the assignments and they respond within 24 hours....they give detail feedback" (F, L632-633.P17). She could submit her papers for review anytime of the day and receive feedback as soon as her paper was reviewed. Participants appreciated having written feedback, Olga shared, "the professor feedback, especially that when she writes something I can print out and keep it, I really like it" (F, L651-652.P17). She also suggested that instructors provide visual and audio materials to scaffold her learning. All participants preferred module by module structured classes as they felt they could manage their work and successfully complete their tasks on time without feeling overwhelmed. Students' experience varied depending on the professor teaching the course.

\section{Perceptions of Learning Experiences}

All participants believed that online courses are flexible and accessible, but they expected to have more interaction and supporting material provided online. Olga posited that online classes saved her travel time because she felt that there were face-to-face classes she had taken in the past that did not benefit her. This finding was similar to Guernsey's (1998a, 1998b) discovery that students characterized online classes as convenient. She shared that she had sat in class the entire period without doing anything constructive other than listening to the professor lecture. Olga was also able to balance her professional and personal life because she could work on her classes at her own pace. She expressed that online classes helped her managed her time effectively because she had more control in arranging her schedule. In addition, Abby valued the written feedback she had received in online classes because she could document the feedback and use it as a reference to improve her work.

\section{DISCUSSION AND CONCLUSION}

The graduate online classes that Abby, Katie, and Olga took were not their first experiences with distance learning. They had taken online courses before with their previous degrees. They based their expectations of their current classes on the online courses they had previously taken. This semester, all participants preferred taking face-to-face classes but, unfortunately, some classes were only offered online. Based on their experiences, they stated that they would consider the professor teaching the course and the level of interaction available, in making their decision to take another online class; this was a similar response to that of participants in Shea et al.'s study (2006).

Online asynchronous learning needs to be used effectively by the instructors and needs to be tailored to the students' needs. Both instructors and course designers need to be responsive to their students' questions, and should provide more visual audio materials that would support student learning. Additionally, instructors need to be actively involved in the discussion board and promoting interaction.

The findings from this study and previous studies show that English language proficiency is an important determinant of an international student's success and satisfaction in an online class (Byram \& Feng, 2006; Ku \& Lohr, 2003; Yan \& Cheng, 2015). Even if an international 
student meets the minimum scores on an English language proficiency test, the scores do not necessarily mean their English language skills will be sufficient for an online class-

Fortunately, this study showed that online courses are an accepted form of education. The structure of online classes module by module helps students to be organized and feel it is doable (Kress et al., 2012). Students shared that this kind of structure alleviates their stress and increases their success of completing their asynchronous online course. Additionally, instructors' technology competence is imperative in determining students experience with classes. For instance, instructor's being able to solve technical issues that students encounter, and their responding promptly to students' emails limit students' challenges and increase their motivation towards learning. It is evident in this study that writing centers support student learning and improve their written communication. Technical issues will always exist with online delivery. Olga had some issues with her online class. At times, she was unable to access key materials or do basic tasks that were required for the course. Instructors must work hard to ensure that the administration of the course goes as planned. Otherwise, all students, especially international ones, will be limited in how much they can learn.

Online education will continue to grow in the $21^{\text {st }}$ century. More people are becoming dependent on taking online courses (Haynie, 2014; Sawang et al., 2013). Instructors of online courses at American institutions should arrange synchronous discussion sessions. Online learning platforms offer flexibility and convenience for students (Braun, 2008; Kress et al., 2012; Morse, 2003). However, the most pressing issue with online courses is meeting the needs and expectations of international students taking these courses. As indicated in the findings of the study, students seem to take online classes for flexibility and convenience (Guernsey 1998a, 1998b; Kress et al., 2012; Morse, 2003). However, the most pressing issue with online courses is incorporating the desired features to meet the needs and expectations of international students taking these courses.

\section{Implications}

Even though online course offerings have increased, there are still issues with online instructor interaction with students. Several recommendations are warranted based on the results presented in this study. Instructors teaching online courses need to become familiar with the course management system. They need to receive training in online teaching before entering the virtual classroom so they can learn the most effective techniques to enhance the online learning experience. They need to provide clear communication with their online students. They need to offer detailed instructions on how to participate in online course activities such as online threaded discussion. They should also define the acceptable guidelines for online class participation. It is important that instructors provide online course activities that encourage more interaction between students. Instructors need to be the facilitators of the discussion board, and so they need to be actively involved in the discussion board, monitor student progress, and give consistent feedback to students. They need to encourage student participation and collaboration. They need to use course design features that clearly explain the course goals and topics.

This study extends previous work concerning graduate students' experiences in asynchronous online classes, and provides online curriculum designers and instructors with insight on international students' challenges and needs. This study reminds administrators, including graduate programs Chairs and Deans, to ensure that instructors who teach online courses use the suitable teaching pedagogy to respond to all of their students' needs. Perhaps, 
new guidelines and evaluation criteria could be used to improve or maintain teaching excellence for teaching diverse learners.

The study is based on a limited number of participants, and limited number of focus groups and interviews. A larger sample from students and possibly from different programs at the same university or students from different universities or from different countries could lead to different results. This research did not receive any specific grant from funding agencies in the public, commercial, or not-for-profit sectors.

\section{REFERENCES}

Allen, I. E., \& Seaman, J. (2014). Class differences: Online education in the United States. Needham, MA: Babson Survey Research Group. Retrieved from https://www.sloanc.org/ publications/survey/pdf/sizing_opportunity.pdf

Baxter, P., \& Jack, S. (2008). Qualitative case study methodology: Study design and implementation for novice researchers. The Qualitative Report, 13(4), 544-559.

Biesenbach-Lucas, S. (2003). Asynchronous discussion groups in teacher training classes: Perceptions of native and non-native students. Journal of Asynchronous Learning Networks, 7(3), 24-46.

Brooks, J. G., \& Brooks, M. G. (1993). In search of understanding: The case for constructivist classrooms. Alexandria, VA: Association for Supervision and Curriculum Development.

Braun, T. (2008). Making a choice: The perceptions and attitudes of online graduate students. Journal of Technology and Teacher Education, 16(1), 63-92.

Byram, M., \& Feng, A. (Eds.). (2006). Living and studying abroad: Research and practice. Toronto, Canada: Multilingual Matters.

Cole, M. T., Shelley, D. J., \& Swartz, L. B. (2014). Online instruction, e-learning, and student satisfaction: A three year study. The International Review of Research in Open and Distributed Learning, 15(6).

Cragg, C. E. (1994a). Distance learning through computer conferences. Nurse Educator, 9(2), 10-14.

Cragg, C. E. (1994b). Nurses' experience of a post-RN course by computer-mediated conferencing: Friendly users. Computers in Nursing, 12(5), 221-226.

Creswell, J. W. (2009). Research design: Qualitative, quantitative, and mixed methods approaches. Thousand Oaks, CA: Sage.

Doolittle, P. E. (1999). Constructivism and online education. Retrieved from http://edpsychserver. ed.vt.edu/workshops/tohe1999/text/doo2.pdf

Einaudi, P. (2011). Two decades of increasing diversity more than doubled the number of minority graduate students in science and engineering. National Center for Science and Engineering Statistics, 11(319), 1-9.

Erichsen, E. A., \& Bolliger, D. U. (2011). Towards understanding

international graduate student isolation in traditional and online environments. Educational Technology Research and Development, 59(3), 309-326.

Erlandson, D. A., Harris, E. L., Skipper, B. L, \& Allen, S. D. (1993). Doing naturalistic inquiry: A guide to methods. Newbury Park, CA: Sage.

Frimming, R. E., \& Bordelon, T. D. (2016). Physical education students'

perceptions of the effectiveness of their distance education courses. Physical Educator, 73(2), 340.

Guernsey, L. (1998a). Distance education for the not so distant. The Chronicle of Higher Education, 44(29), A29-A30.

Guernsey, L. (1998b). Trading a classroom for a keyboard and eye contact for e-mail. The Chronicle of Higher Education, 44(25), A25-A26.

Han, E. (2007). Academic discussion tasks: A Study of EFL students' perspectives. Asian EFL Journal Press, 9(1), 8-21. 
Haynie, D. (2014, May 24). U.S. online degrees pose challenges for international students. U.S. World Report News. Retrieved from http://www.usnews.com/education/online-education/articles/ 2014/05/23/us-online-degrees-pose-challenges-for-international-students

Harasim, L. (2017). Learning theory and online technologies. Taylor \& Francis.

Hennink, M. M. (2013). Focus group discussions. Oxford University.

Hofstede, G. (2005). Cultures and organizations: Software of mind ( $3^{\text {rd }}$ ed.). New York, NY: McGrawHill.

International Prospective Students. (n.d.). In Texas Tech University Graduate Admission. Retrieved from https://www.depts.ttu.edu/gradschool/admissions/international/procedures

Jackson, L. C., Jones, S. J., \& Rodriguez, R. C. (2010). Faculty actions that result in student satisfaction in online courses. Journal of Asynchronous Learning Networks, 14(4), 78-96.

Jonassen D H (2000) Transforming learning with technology: beyond Modernism and Post-modernism or whoever controls the technology creates the reality. Educational Technology 40 (2), 21-25.

Ko, S., \& Rossen, S. (2017). Teaching online: A practical guide. Taylor \& Francis.

Kress, H., Thering, A., Lalonde, C., Kim, S., \& Cleeton, L. (2012). Faculty reflections on online course development and implementation for teacher education. International Journal of Technology, Knowledge \& Society, 8(1), 73-83.

$\mathrm{Ku}$, L., \& Lohr, L. (2003). A case study of Chinese students' attitudes toward their first online learning experience. Educational Technology Research and Development, 51(3), 94-102.

Landis, B. J., \& Wainwright, M. (1996). Computer conferencing: Communication for distance learning, Nurse Educator, 21(2), 9-14.

Lee J. W. (2010). Online support service quality, online learning acceptance, and student satisfaction. Internet and Higher Education, 13(4), 277283.

Lincoln, Y. S., \& Guba, E. G. (1985). Naturalistic inquiry. Beverly Hills, CA: Sage.

Marshall, G. (2005). The purpose, design and administration of a questionnaire for data collection. Radiography, 11(2), 131-136. doi:10.1016/j.radi.2004.09.002

Merriam, S. (1988). Case study research in education: A qualitative approach. San Francisco, CA: Jossey-Bass.

Merriam, S. B., \& Tisdell, E. J. (2016). Qualitative research: A guide to design and implementation. San Francisco, CA: Jossey-Bass.

Morse, K. (2003). Does one size fit all? Exploring asynchronous learning in a multicultural environment. Journal of Asynchronous Learning Networks, 7(1), 37-55.

Moller L (1998) Designing communities of learners for asynchronous distance education. Educational Technology Research and Development 6(4) 115-122.

Petraglia, J. (1998). The real world on a short leash: the (mis)application of constructivism to the design of educational technology. Educational Technology Research and Development 46(3) 53-65.

Palloff, R. M., \& Pratt, K. (2000). Making the transition: Helping teachers to teach online. Retrieved from_http://files.eric.ed.gov/fulltext/ED452806.pdf

Plath, D. W. (1990). Fieldnotes, filed notes, and the conferring of note. Fieldnotes: The makings of anthropology, 371-384

Rawlings, M., \& Sue, E. (2013). Preparedness of Chinese students for American culture and communicating in English. Journal of International Students, 3(1), 29-40.

Rovai, A. P. (2002). Development of an instrument to measure classroom community. The Internet and Higher Education, 5(3), 197-211.

Shea, P., Li, C., \& Pickett, A. (2006). A study of teaching presence and student sense of learning community in fully online and web-enhanced college courses. The Internet and Higher Education, 9(3), 175-190.

Simonson, M., Smaldino, S., \& Zvacek, S. (2015) Teaching and learning at a distance: Foundations of distance education $\left(6^{\text {th }}\right.$ ed.). Boston, MA: Pearson Education.

Sawang, S., Newton, C., \& Jamieson, K. (2013). Increasing learners' satisfaction/intention to adopt more e-learning, Education + Training, 55(1), 83-105. 
Tootoonchi, N. (2016). The importance of students' perceptions of the online learning environment in mathematics classes: literature review. International Journal of Education Research, 11(1).

Vonderwell, S. (2003). An examination of asynchronous communication experiences and perspectives of students in an online course: A case study. The Internet and Higher Education 6(1), 77-90.

Vygotsky, L. S. (1978). Mind in society: The development of higher psychological processes. M. Cole, V. John-Steiner, S. Scribner, \& E. Souberman (Eds.). Cambridge, MA: Harvard University.

What is Computer-Mediated Communication (CMC)? (n.d.). In Techopedia. Retrieved from https://www.techopedia.com/definition/392/computer-mediatedcommunication-cmc

Yan, W., \& Cheng, L. (2015). How language proficiency contributes to Chinese students' academic success in Korean universities. Language Testing in Asia, 5(1), 1-19.

Yin, R. (2003). Case study research: Design and methods ( $3^{\text {rd }}$ ed.). Thousand Oaks, Beverly Hills, CA: Sage publications

Yin, R. (2014). Case study research: Design and methods ( $5^{\text {th }}$ ed.) Thousand Oaks, CA: Sage.

Wickersham, L. E. \& McGee, P. (2008). Perceptions of satisfaction and deeper learning in an online course. Quarterly Review of Distance Education, 9(1), 73-83.

Zhang, Z., \& Kenny, R. F. (2010). Learning in an online distance education course: Experiences of three international students. International Review of Researching in Open and Distributed Learning, 11(1), 17-36.

TALA KARKAR-ESPEART, PhD, is a student at Texas Tech University (TTU). She is currently working as a Research Assistant at the TTU College of Education, where she is investigating students' perceptions of online course. Her research interests are in online classes, literacy coaching, multiculturalism, new literacies. Email: tala.karkar@ttu.edu 